\title{
A study on health and the association between overweight/obesity and otorhinolaryngological diseases in 6- to 17-year-old children from Wroclaw, Poland
}

Tomasz Zatoński, Katarzyna Pazdro-Zastawny, Mateusz Kolator, Joanna Krajewska, Alicja Basiak-Rasała, Sara Górna, Michał Zatoński

Wroclaw Medical Univeristy, Wroclaw, Poland

Submitted: 16 January 2019; Accepted: 21 July 2019

Online publication: 15 July 2020

Arch Med Sci 2022; 18 (2): 413-421

DOI: https://doi.org/10.5114/aoms.2020.97285

Copyright (c) 2020 Termedia \& Banach

\section{Abstract}

Introduction: Childhood overweight and obesity have become a global problem in the past three decades. There are very few studies which examine the correlation between body mass index (BMI) and the development of otorhinolaryngological diseases in children. The objective of the study was to determine the association between overweight or obesity in children and the occurrence of otorhinolaryngological diseases.

Material and methods: The survey study was based on a parent-reported multidisciplinary questionnaire on children's medical status among elementary and junior high school children in the city of Wroclaw, the capital city of Poland's Lower Silesia region. The children were taking part in the prohealth campaign "Let's Get the Kids Moving".

Results: The study was conducted among 2,913 children. A statistically significant correlation was observed between the assessment of the children's $\mathrm{BMI}$ and the occurrence of adenoid hypertrophy. Adenoid hypertrophy was more common in the overweight and obese children. The children with adenoid hypertrophy had higher BMI than the children without adenoid hypertrophy. There was a statistically significant correlation between BMI and the incidence of adenoidectomy. There was a statistically significant correlation between BMI and the incidence of tonsillectomy.

Conclusions: The development and introduction of preventive programs like "Let's Get the Kids Moving" in the future will contribute to building a healthier society. The study findings suggest that primal prevention may lead to a decrease in the development of otorhinolaryngological diseases. We also showed that higher body mass correlates with higher prevalence of otorhinolaryngological diseases. Further studies are needed to establish the etiopathology of this association.

Key words: obesity, prevention, public health, body mass index.

\section{Introduction}

The increasing number of adults and children affected by overweight and obesity has become a global concern in the past 30 years. A 2017 report from the Commission on Ending Childhood Obesity of the World Health Organization (WHO) estimated that the number of overweight children increased from 31 million in 1990 to 42 million in 2015 [1]. According to the $\mathrm{WHO}$, over $22 \%$ of children in Poland are affected by
Corresponding author: Assoc. Prof. Tomasz Zatoński Department and Clinic of Otolaryngology, Head and Neck Surgery Wroclaw Medical Univeristy 213 Borowska St 50-556 Wroclaw, Poland E-mail: tomasz.zatonski@umed.wroc.pl 
overweight or obesity. Obesity has been considered a non-communicable disease and is seen as a health challenge.

Excessive body weight in childhood contributes to an increased risk of overweight in adulthood. A study by Nader revealed that children with a body mass index (BMI) above the $85^{\text {th }}$ percentile, or with a $\mathrm{BMI}$ in the high reference range, were more prone to remain affected by obesity into adulthood than children whose BMI was below the $50^{\text {th }}$ percentile [2].

It has been established that overweight and obesity in childhood constitute the most common risk factor for the development and premature onset of cardiovascular diseases and that it is strongly connected with a higher risk of hyperinsulinemia, impaired glucose tolerance, type 2 diabetes mellitus, dyslipidemia, hypertension and adverse changes in the walls of blood vessels [3]. Kelsey et al. stated that the health effects related to excessive body weight in childhood may have long-term sequelae in adulthood - despite normalization of body weight - and, consequently, may increase the likelihood of early morbidity and mortality [4].

Childhood obesity may predispose one to otorhinolaryngological diseases by interfering with the immune system and mechanically through an excess concentration of visceral fat. The consequences of increased body mass include the development of abdominal obesity and, to some extent, ectopic fat deposition in adulthood. An association between obesity, adenotonsillar hypertrophy and obstructive sleep apnea (OSA) has been reported. The role of increased body weight in the aetiopathogenesis of those conditions is not fully understood. The increased prevalence of both adenoid and tonsillar hypertrophy among the pediatric population affected by obesity in comparison to normal weight peers was reported. It may be a connected with endocrine changes. Endocrine mediated somatic growth in children promotes accumulation of larger and/or heavier fat pads, soft palate, and tongue [5]. Also obesity may contribute to the development of OSA by narrowing the upper airways through an accumulation of fat. Fat-induced obstruction enhances inflammatory responses [6]. A study conducted by Rubinstein [7] revealed the presence of nasal inflammation, in the form of an increased number of polymorphonuclear leukocytes and the concentrations of bradykinin and vasoactive intestinal peptide, in patients with OSA and suggested that it influences upper airway obstruction in OSA. As adipose tissue is considered to be immunologically active, an association between obesity and chronic otorhinolaryngological inflammatory diseases including adenoid and tonsillar hypertro- phy may be connected with increased secretion of inflammation-related substances in youths with high BMI.

There are very few studies which examine the correlation between $\mathrm{BMI}$ and the development of otorhinolaryngological diseases in children.

The aim of this study was to determine the association between overweight or obesity in children and the occurrence of otorhinolaryngological diseases.

In particular, answers to the following questions were sought:

1. Which otolaryngological diseases occur among children affected by overweight and obesity?

2. Is there a relationship between BMI and the occurrence of otorhinolaryngological diseases?

\section{Material and methods}

The survey study was conducted from September 2016 to July 2017. It was based on a parent-reported multidisciplinary questionnaire on children's medical status among elementary and junior high school children in the city of Wroclaw, the capital city of Poland's Lower Silesia region.

Parents of 2,913 children - aged between 6 and 17 years and recruited from 34 elementary and junior high schools in the city of Wroclaw completed and returned the questionnaire (33\% response rate; the questionnaire was handed out to 10,000 families). The children were taking part in the pro-health campaign "Let's Get the Kids Moving" ("Uruchamiamy dzieciaki”). "Let's Get the Kids Moving" is an obesity prevention program. The campaign was launched in 2016 and created and organized by the employees of Wroclaw Medical University and the "Run for Health" Foundation (Fundacja "Biegaj dla Zdrowia") and addressed to physical education teachers, parents, educators and trainers.

The aim of the campaign is to promote a healthy lifestyle, physical activity and a balanced diet and to draw attention to the problem of overweight and the resulting diseases in children by 1) organizing sports events and 2) educating teachers and parents during periodic meetings.

The questionnaire was designed especially for this study by the team of specialists including otorhinolaryngologists from Wroclaw Medical University and the University Clinical Hospital in Wroclaw. The questionnaires regarding children's medical condition were distributed to school coordinators and handed out to parents during periodic school meetings. The survey inquired as to whether the child/children had suffered or currently suffered from the following conditions or groups of conditions: adenoid hypertrophy, tonsillar hypertrophy or obstructive sleep apnea syndrome. The other questions concerned otolaryngological conditions 
(where applicable) and consisted of: adenoidectomy and/or tonsillectomy and the presence of complications after such operation(s).

Body mass index was calculated from self-reported weight and height measurements of the participants. The BMI was calculated by dividing the body mass in kilograms by the square of the body height in meters. Overweight and obesity were determined on the basis of the percentile categories according to current reference charts for Polish children correlated by body weight and height $[8,9]$. The participants were divided into five groups according to current reference charts for Polish children correlated by body weight and height: 1) underweight; 2) slim; 3) normal body weight; 4) overweight; and 5) affected by obesity.

Permission for the subjects to participate in the study described in this manuscript was approved and granted by the Local Ethics Committee of the Medical University in Wroclaw, Poland (KB - 738/2018). All participants took part in the study voluntarily and were able to discontinue their participation at any time without repercussion. The participants and their legal guardians were informed of the nature of the study and in each case they formally expressed their consent to the study. This study was performed in accordance with the ethical standards laid down in the 1964 Declaration of Helsinki and its later amendments.

\section{Statistical analysis}

Statistical analysis was performed using the Statistica v.13 software package (StatSoft Inc., Tulsa, OK. USA). All quantitative parameters (BMI, frequency of consumption of specific products and activities) in all subgroups were examined for normality of distribution using the KolmogorovSmirnov test or Shapiro-Wilks test, if the numbers in the subgroups were less than 50, at the threshold level of significance $p<0.05$. Quantitative characteristics of the study group are shown in tables as means (M) and standard deviations (SD), and nominal characteristics are shown as numbers $(n)$ and percentages (\%). The significance of differences in the quantitative parameters in two groups of children (e.g. differing in otitis media with middle hypertrophy or hypertrophy of the third tonsil) was verified by the Mann-Whitney $U$ test. Hypotheses on the independence of nominal and ordinal characteristics were verified using Pearson's $\chi^{2}$ test. For all tests, a significance threshold of $p<0.05$ was used.

\section{Results}

The survey study was conducted among 2,913 children (1,418 girls and 1,495 boys). The majority of the surveys were completed by mothers: 2,407 surveys in total (82.6\%). 456 surveys were filled in by fathers (15.7\%) and 50 (1.7\%) by another guardian. A sociodemographic analysis of the study participants in terms of BMI categorization is presented in Table I.

\section{Adenoid hypertrophy}

A statistically significant correlation was observed between the assessment of the children's $\mathrm{BMI}$ and the occurrence of adenoid hypertrophy (Figure 1). Adenoid hypertrophy was more common in children affected by overweight and obesity $(p<0.05)$.

A statistically significant correlation was present between BMI values in the groups and the presence of adenoid hypertrophy (Figure 2, $p<0.01$ ). The children with adenoid hypertrophy had higher $\mathrm{BMI}$ than the children without adenoid hypertrophy (18.4 vs. $\left.17.9 \mathrm{~kg} / \mathrm{m}^{2} ; p=0.002\right)$.

\section{Adenoidectomy/tonsillectomy/tonsillotomy}

There was a statistically significant correlation between $\mathrm{BMI}$ and the incidence of adenoidectomy and tonsillectomy (Figure 3, $p<0.001$; Figure 4 , $p<0.001$ ). Adenoidectomy and tonsillectomy had been performed significantly more often among the children affected by overweight and obesity ( $p<0.001, p<0.05$, respectively).

\section{Obturative sleep apnea}

The values for the children's otorhinolaryngological status concerning obstructive sleep apnea syndrome (OSA/OSAS) and adenoid hypertrophy are shown in Tables II and III.

There was no statistically significant association between BMI and the prevalence of obturative sleep apnea $(p>0.05)$.

There was a statistically significant association between BMI and the prevalence of adenoid hypertrophy $(p<0.01)$. In slim children, adenoid hypertrophy occurred significantly less often than in children with normal body weight $(21.8 \%$ vs. $26.7 \% ; p=0.026)$, in overweight children $(21.8 \%$ vs. $30.9 \% ; p=0.004)$ and in children affected by obesity (21.8\% vs. $35.7 \%$; $p=0.002)$.

\section{Discussion}

Childhood overweight and obesity have become a global problem in the past three decades. Cultural and socio-economic changes, increased urbanization, advanced computerization and technological progress have contributed to the increased prevalence of obesity and overweight. In developed countries, nourishment is more accessible and affordable, hard physical work that in 


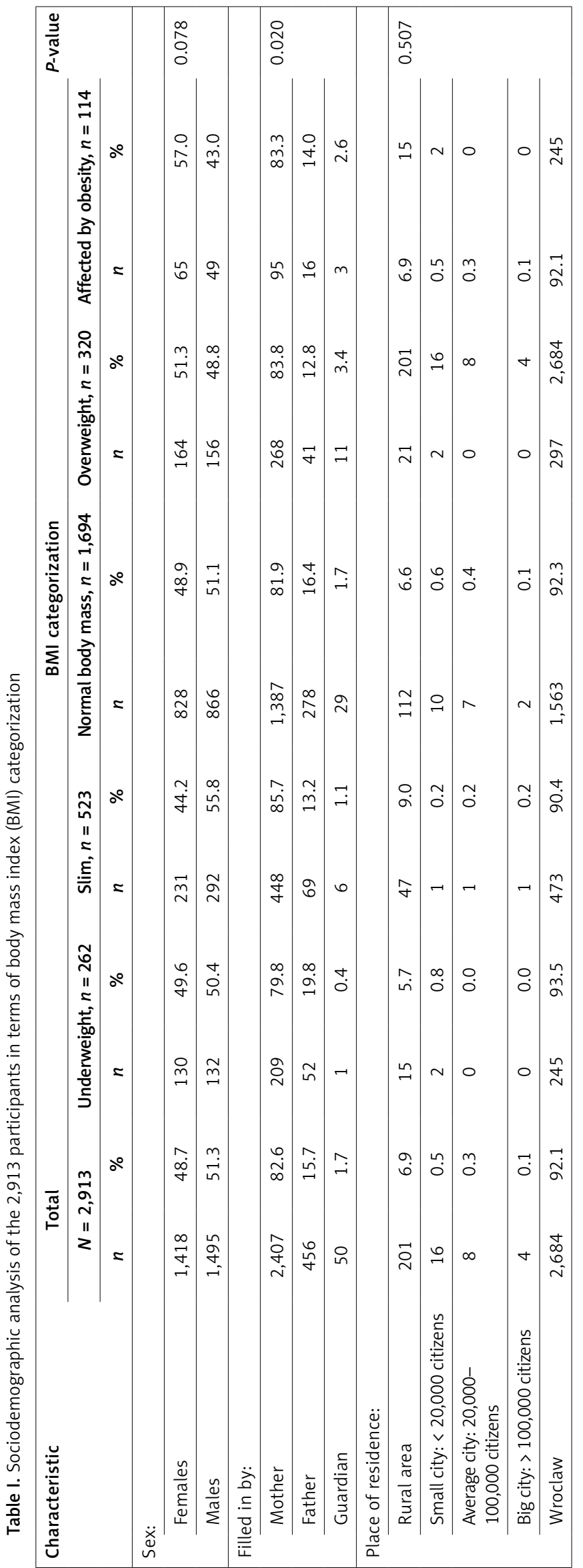

many cases involved human labor is constantly being replaced by machines, and car ownership has increased along with labor-saving devices and techniques. In a study by Sidell et al. [10], approximately 95\% of children were affected by obesity, representing $22.2 \%$ of the U.S. population between the ages of 6 and 17 years.

The prevalence of overweight and obesity in Polish children, according to a WHO report, was approximately $22 \%$. A radical improvement in socioeconomic conditions in Poland has promoted a higher prevalence of excess weight in childhood in recent years $[3,11]$. The international OLAF Study by Kułaga et al. [8] showed that almost $20 \%$ of Polish children are affected by overweight or obesity and that $30 \%$ had waist circumference measurements above the international cardiovascular risk threshold. The study also revealed that the distributions of height, weight and BMI in children and adolescents differed from those of children in the international growth reference charts. In a study by Czyż et al., the prevalence of overweight and obesity was $13.1 \%$ and $4.06 \%$, respectively [12].

In our study, overweight was present in $11 \%$ of the children $(51.3 \%$ of girls and $48.8 \%$ of boys), while obesity was reported in $4 \%$ of them ( $57 \%$ of girls and $43 \%$ of boys).

According to Kutaga et al. the prevalence of excessive body weight in Polish children and adolescents was medium to high in comparison to the other European countries. In a nationwide survey study, conducted in Poland in 2007-2009 and covering a population of elementary and high school pupils (17 427 children), the prevalence of overweight and obesity was determined using three childhood obesity definitions: the Centers for Disease Control and Prevention (CDC), the International Obesity Task Force (IOTF), and the WHO. Overweight or obesity was present in the range 14.6-19.4\% of boys and $10.3-13.0 \%$ of girls aged $13-18$ years, including obesity in older children (13-18 years) in 
A

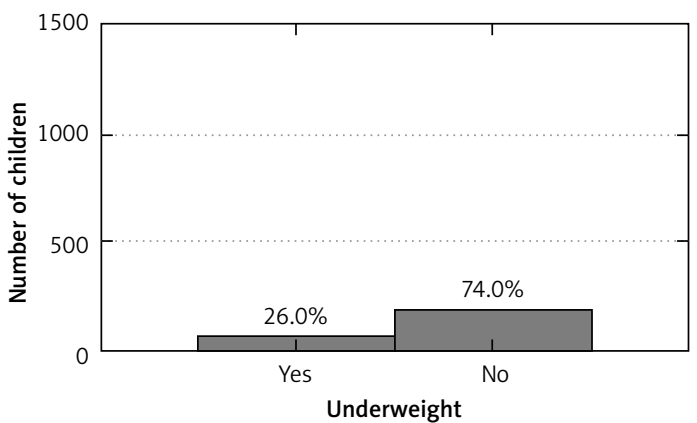

C

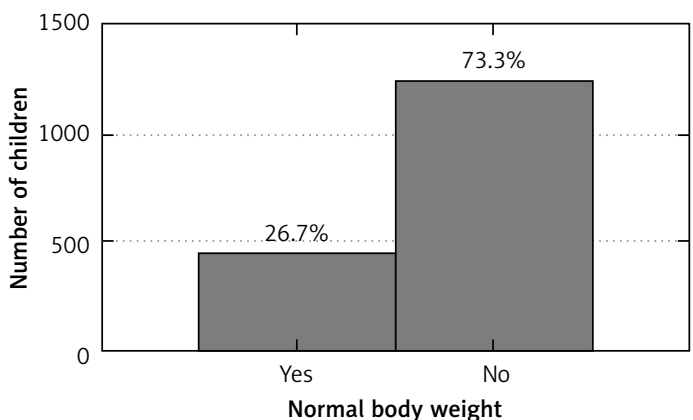

E

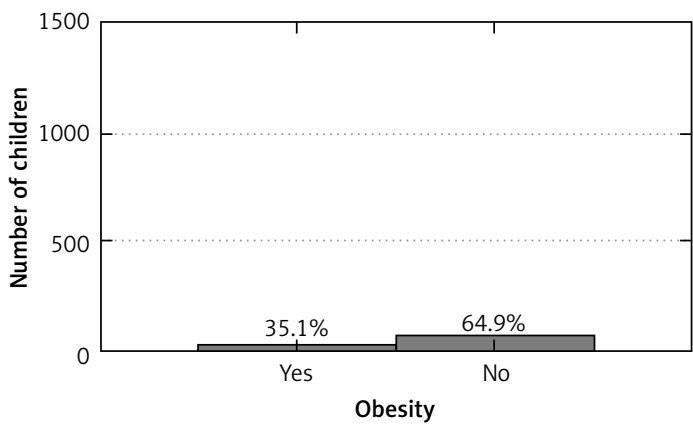

the range $3.4-5.0 \%$ of boys, and $2.0-2.6 \%$ of girls. The prevalence of obesity in younger children aged $7-12$ years was in the range $5.5-13.1 \%$ of boys and $3.6-6.4 \%$ of girls [13]. Research conducted by Wozniacka among a group of 3405 Polish children aged 5-14 in 2009-2010 estimated body weight according to different BMI cut-offs: IOTF, CDC and the Polish 2010 standard. The study showed that overweight occurred in 15\%, $11.3 \%$ and $9.5 \%$ (IOTF, CDC, Polish 2010, respectively) of boys and $15.5 \%, 11.6 \%$ and $9.9 \%$ of girls. $3.3 \%, 6.1 \%$ and $3.3 \%$ of boys (IOTF, CDC, Polish 2010, respectively) and $3.4 \%, 6.3 \%$ and $5.7 \%$ of girls were affected by obesity. The study estimated the prevalence of obesity and overweight according to the protocol of the European Childhood Obesity Group [14]. Similar results were obtained by Tomaszewski et al. In a study conducted on a pupils from primary schools in Warsaw, Poland (367 girls and 424 boys aged $6.5-10.5$ years) and based on BMI $15 \%$ of all participants were classified as overweight, and
B

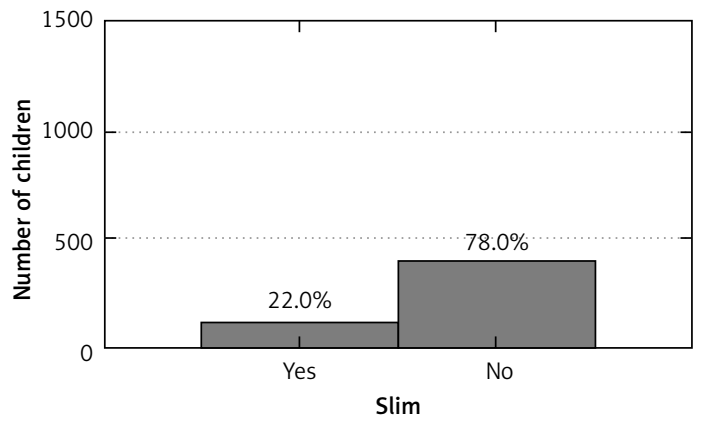

D

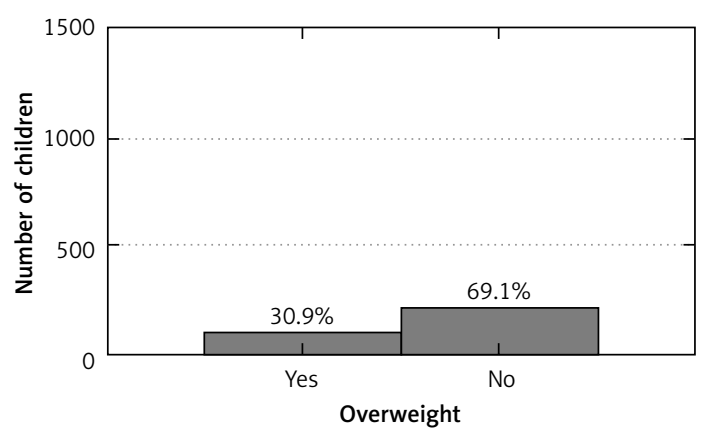

Figure 1. Prevalence of adenoid hypertrophy according to body mass index (Pearson's $\chi^{2}$ test). Pearson's $\chi^{2}$ test: $\chi^{2}=13.1, \mathrm{~d} f=4, p=0.011$

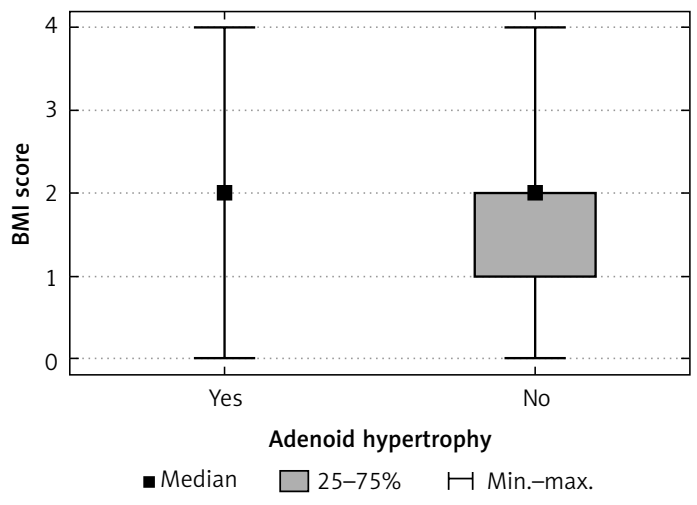

Figure 2. Prevalence of adenoid hypertrophy according to body mass index (0 - underweight, 1 - slim, 2 - normal body weight, 3 - overweight, 4 - affected by obesity) (Mann-Whitney $U$ test). $U$ Mann-Whithey test; $Z=3.072, p=0.002$

approximately $4 \%$ of girls and $6 \%$ of boys aged 7-10 were obese [15].

In another study, the body weight, height and $\mathrm{BMI}$ of 70,329 children aged between 6 and 13 
A

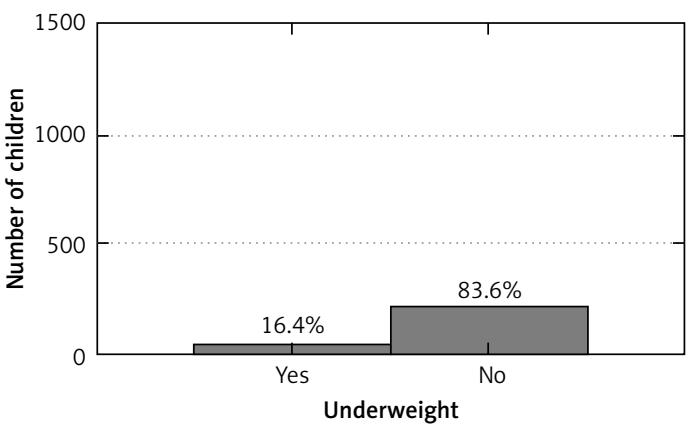

C

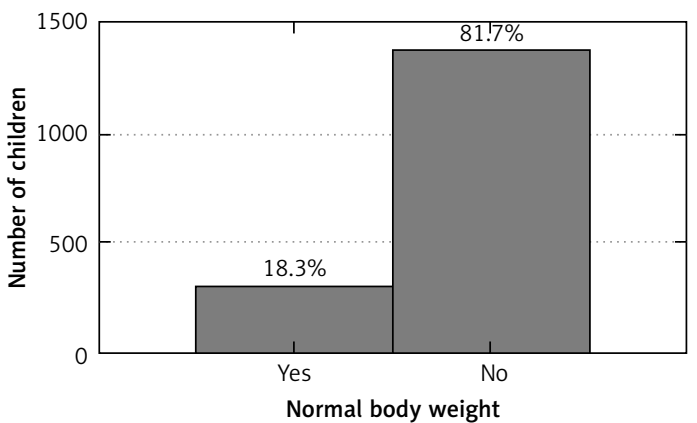

E

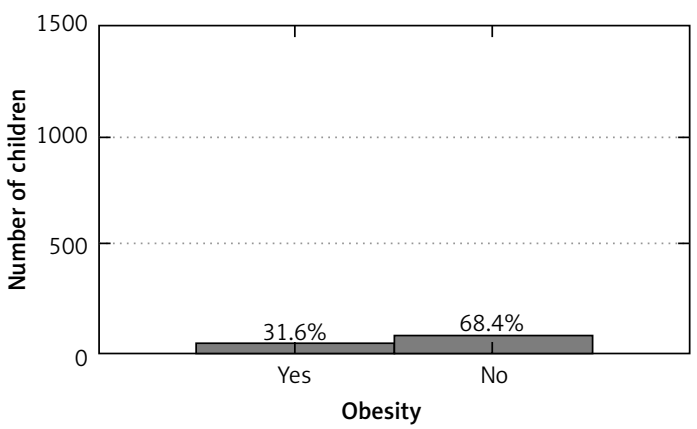

years were studied during annual child health measurements in Gdańsk schools between 1992 and 2012. Brzeziński et al. [16] did not identify any trend in increasing prevalence of overweight or obesity among the children studied. However, an age-related increase in the prevalence of excess body weight among 6-, 7-, and 12-year-old children born between 1993 and 1997 was noted. The prevalence of excess body weight was higher in girls than in boys from all age categories, except 12- and 13-year-old children, in whom no gender-specific differences were documented.

In a study by Daar et al. [17], children affected by obesity aged between 3 and 18 years had a higher prevalence of adenotonsillar hypertrophy compared to normal-weight peers. This could be connected with endocrine-mediated somatic growth [17].

In another study [18], it was revealed that children with adenoid and tonsil hypertrophy had lower high-density lipoprotein cholesterol (HDL-C) than normal children. The authors state
B

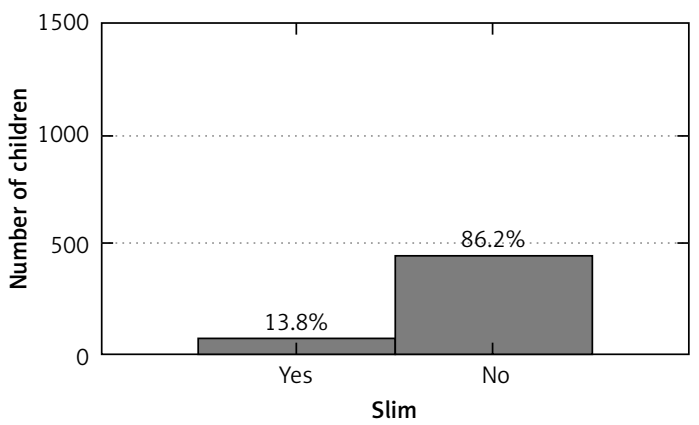

D

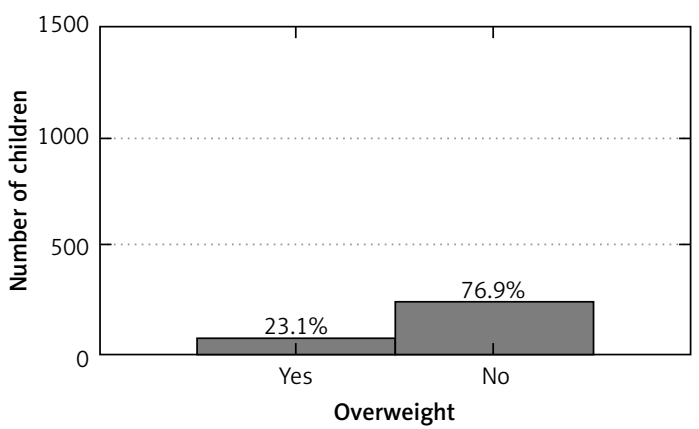

Figure 3. The correlation between adenoidectomy and body mass index (Pearson's $\chi^{2}$ test). rho-Spearman $=-0.081, p<0.001$. Pearson $\chi^{2}$ test: $\chi^{2}=26.2$ $\mathrm{d} f=4, p<0.001$

that HDL-C may be a sensitive indicator of serum lipid changes in sleep-disordered breathing (SDB) children, as the HDL-C concentration was lower in children with more enlarged adenoids and tonsils.

Children affected by obesity have an increased risk of obesity-associated comorbidities, including obstructive sleep apnea (OSA), compared to their normal-weight counterparts. Adenotonsillar hypertrophy and, consequently, the development of airway obstruction is a significant cause of OSA in children affected by obesity and those not affected by obesity. OSA is a breathing disorder during sleep which is characterized by the repetitive collapse of the upper respiratory tract. In the United States, the prevalence of this condition is estimated to be $3-7 \%$ in men and $2-5 \%$ in women [19]. Among patients with a BMI greater than 28 , OSA was reported in $41 \%$ of subjects [20]. Wang et al. [21] compared palatine tonsil size (volume, weight, width, height and thickness) in two groups of children with SDB, those affected by obesity and those not affected by obesity. 
A

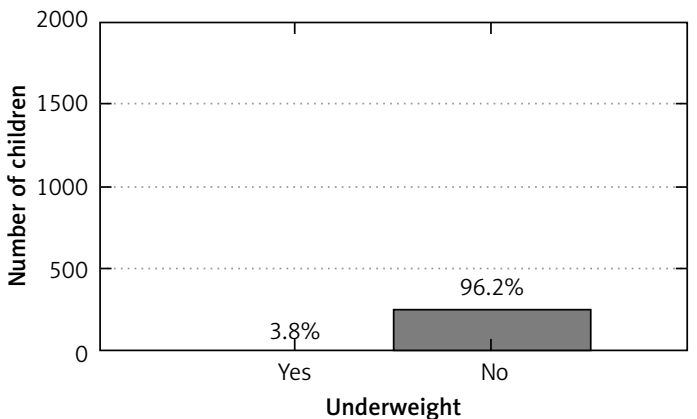

C

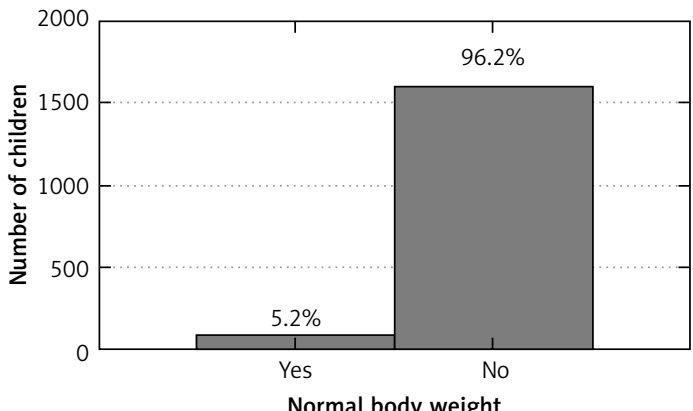

E

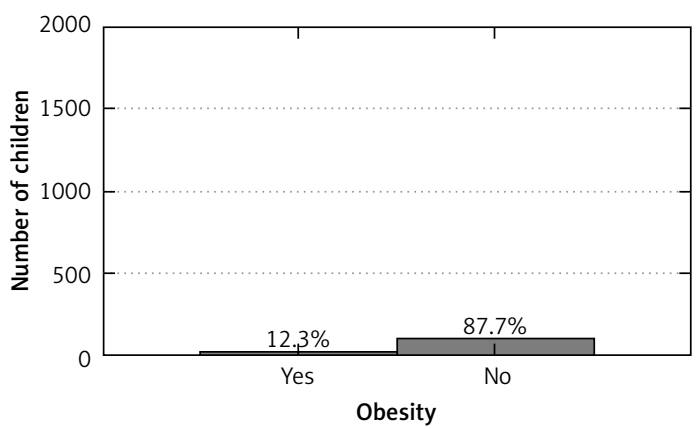

$B$

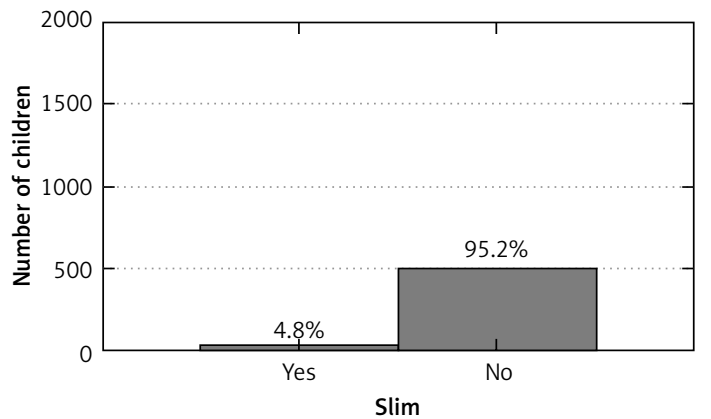

D

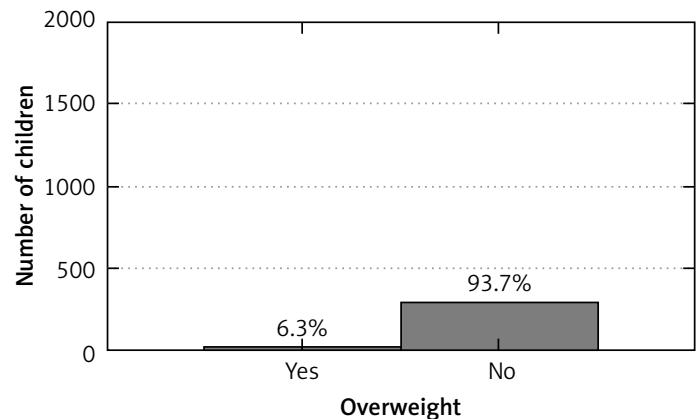

Figure 4. The correlation between tonsillectomy and body mass index (Pearson's $\chi^{2}$ test). rho-Spearman $=-0.045, p=0.016$. Pearson $\chi^{2}$ test: $\chi^{2}=12.9$, $\mathrm{d} f=4, p=0.012$

Table II. Answers to the question, “Does the child suffer from obstructive sleep apnea/sleep apnea syndrome?” in groups of children categorized by body mass index (BMI)

\begin{tabular}{|c|c|c|c|c|c|c|c|c|c|c|c|c|c|}
\hline \multirow[t]{3}{*}{ Response } & \multirow{2}{*}{\multicolumn{2}{|c|}{$\begin{array}{c}\text { Total } \\
N=2,764\end{array}$}} & \multicolumn{10}{|c|}{ BMI categorization } & \multirow[t]{3}{*}{$P$-value } \\
\hline & & & \multicolumn{2}{|c|}{$\begin{array}{l}\text { Underweight, } \\
n=250\end{array}$} & \multicolumn{2}{|c|}{$\begin{array}{c}\text { Slim, } \\
n=499\end{array}$} & \multicolumn{2}{|c|}{$\begin{array}{c}\text { Normal weight, } \\
n=1,604\end{array}$} & \multicolumn{2}{|c|}{$\begin{array}{l}\text { Overweight } \\
n=308\end{array}$} & \multicolumn{2}{|c|}{$\begin{array}{c}\text { Affected by } \\
\text { obesity, } n=103\end{array}$} & \\
\hline & $n$ & $\%$ & $n$ & $\%$ & $n$ & $\%$ & $n$ & $\%$ & $n$ & $\%$ & $n$ & $\%$ & \\
\hline No (0) & 2,697 & 97.6 & 242 & 96.8 & 483 & 96.8 & 1,572 & 98.0 & 299 & 97.1 & 101 & 98.1 & 0.463 \\
\hline Yes (1) & 67 & 2.4 & 8 & 3.2 & 16 & 3.2 & 32 & 2.0 & 9 & 2.9 & 2 & 1.9 & \\
\hline
\end{tabular}

Table III. Answers to the question, "Has the child ever had adenoid hypertrophy?" in groups of children categorized by body mass index (BMI)

\begin{tabular}{|c|c|c|c|c|c|c|c|c|c|c|c|c|c|}
\hline \multirow[t]{3}{*}{ Response } & \multirow{2}{*}{\multicolumn{2}{|c|}{$\begin{array}{c}\text { Total } \\
N=2,874\end{array}$}} & \multicolumn{10}{|c|}{ BMI categorization } & \multirow[t]{3}{*}{$P$-value } \\
\hline & & & \multicolumn{2}{|c|}{$\begin{array}{l}\text { Underweight, } \\
\quad n=259\end{array}$} & \multicolumn{2}{|c|}{$\begin{array}{c}\text { Slim, } \\
n=514\end{array}$} & \multicolumn{2}{|c|}{$\begin{array}{c}\text { Normal weight, } \\
\qquad n=1,672\end{array}$} & \multicolumn{2}{|c|}{$\begin{array}{l}\text { Overweight, } \\
n=317\end{array}$} & \multicolumn{2}{|c|}{$\begin{array}{c}\text { Affected by } \\
\text { obesity, } n=112\end{array}$} & \\
\hline & $n$ & $\%$ & $n$ & $\%$ & $n$ & $\%$ & $n$ & $\%$ & $n$ & $\%$ & $n$ & $\%$ & \\
\hline No (0) & 2,110 & 73.4 & 191 & 73.7 & 402 & 78.2 & 1,226 & 73.3 & 219 & 69.1 & 72 & 64.3 & \multirow{2}{*}{0.008} \\
\hline Yes (1) & 764 & 26.6 & 68 & 26.3 & 112 & 21.8 & 446 & 26.7 & 98 & 30.9 & 40 & 35.7 & \\
\hline
\end{tabular}


The study revealed that in children affected by obesity tonsils were larger than in normal-weight control subjects with SDB. This finding suggests that larger palatine tonsils may have a greater effect on upper airway obstruction in children affected by obesity than in normal-weight children with SDB. In another study, Arens et al. [22] studied lymphoid tissues in children affected by obesity with obstructive sleep apnea syndrome (OSAS) versus controls affected by obesity. Patients with OSAS had larger adenoid, tonsils and retropharyngeal nodes. The authors revealed that BMI did not correlate with the size of lymphoid tissues. However, children affected by obesity with OSAS demonstrated larger parapharyngeal fat pads and abdominal visceral fat compared to normal-weight peers.

The volume of upper airway tissue structures in OSAS patients is enlarged and is involved in the development of sleep apnea along with other factors, such as age, craniofacial size, being male and genetic factors [18]. A higher prevalence of OSAS was observed in children and adults, and a higher incidence of OSAS in children affected by obesity was also reported [5].

Several possible limitations of the study need to be considered. The children's weight and height were self-reported by their parents or legal guardians. Self-reported values are believed to underestimate BMI. In the study we are conducting this year, the children's weight and height will be measured by the nurse. Also, as otorhinolaryngological diseases were also self-reported, there may be issues about the accuracy of the diagnosis.

In conclusion, we strongly believe that the development and introduction of preventive programs like "Let's Get the Kids Moving" in the future will contribute to building a healthier society. The study findings suggest that primal prevention may lead to a decrease in the development of otorhinolaryngological diseases.

Our research indicates that higher body mass correlates with higher prevalence of otorhinolaryngological diseases. Overweight and obesity may be considered as a potential contributor to the development of those conditions. Further studies are needed to establish the etiopathology of this association.

Our further future studies will focus on longitudinal assessments of weight, height, BMI and otorhinolaryngological diseases in order to establish trends and changes in overweight and obesity and the development of non-communicable diseases in the pediatric population of Wroclaw.

\section{Conflict of interest}

The authors declare no conflict of interest.

\section{References}

1. WHO. Report of the Commission on Ending Childhood Obesity: implementation plan: executive summary; 2017. Available from: https://www.who.int/end-childhood-obesity/publications/echo-plan-executive-summary/en/

2. Nader PR, O'Brien M, Houts R, et al.; National Institute of Child Health and Human Development Early Child Care Research Network. Identifying risk for obesity in early childhood. Pediatrics 2006; 118: e594-601.

3. Stańczyk J, Kierzkowska B, Podolec P, et al. Polish forum for prevention guidelines on cardiovascular diseases prevention in children and adolescents. Kardiol Pol 2010; 68: 605-8.

4. Kelsey MM, Zaepfel A, Bjornstad P, Nadeau KJ. Age-related consequences of childhood obesity. Gerontology 2014; 60: 222-8.

5. Narang I, Mathew JL. Childhood obesity and obstructive sleep apnea. J Nutr Metab 2012; 2012: 134202.

6. O'Brien LM, Sitha S, Baur LA, Waters KA. Obesity increases the risk for persisting obstructive sleep apnea after treatment in children. Int J Pediatr Otorhinolaryngol 2006; 70: 1555-60.

7. Rubinstein I. Nasal inflammation in patients with obstructive sleep apnea. Laryngoscope 1995; 105: 175-7.

8. Kułaga Z, Litwin M, Tkaczyk M, et al. Polish 2010 growth references for school-aged children and adolescents. Eur J Pediatr 2011; 170: 599-609.

9. de Onis M, Onyango AW, Borghi E, Siyam A, Nishida C, Siekmann J. Development of a WHO growth reference for school-aged children and adolescents. Bull World Health Organ 2007; 85: 660-7.

10. Sidell D, Shapiro NL, Bhattacharyya N. Obesity and the risk of chronic rhinosinusitis, allergic rhinitis, and acute otitis media in school-age children. Laryngoscope 2013; 123: 2360-3.

11. Niemirska A, Litwin M, Grenda R. Obesity and arterial hypertension - an emerging pediatric problem. Pediatr Pol 2004; 79: 343-50.

12. Czyż SH, Toriola AL, Starościak W, Lewandowski M, Paul Y, Oyeyemi AL. Physical fitness, physical activity, sedentary behavior, or diet-what are the correlates of obesity in polish school children? Int J Environ Res Public Health 2017; 14: 664.

13. Kułaga Z, Grajda A, Gurzkowska B, Wojtyło M, Góźdź M, Litwin $M$. The prevalence of overweight and obesity among Polish school-aged children and adolescents. Przegl Epidemiol 2016; 70: 641-51.

14. Woźniacka R, Bac A, Kowal M, Matusik S. Differences in the prevalence of overweight and obesity in 5- to 14-year-old children in Kraków, Poland, using three national BMI cut-offs. J Biosoc Sci 2018; 50: 365-79.

15. Tomaszewski P, Żmijewski P, Milde K, SienkiewiczDianzenza E. Weight-height relationships and central obesity in 7-year-old to 10-year-old Polish urban children: a comparison of different BMI and WHtR standards. J Physiol Anthropol 2015; 34: 34.

16. Brzeziński M, Jankowski M, Jankowska A, Niedzielska A, Kamińska B. Is there a rapid increase in prevalence of obesity in Polish children? An 18-year prospective observational study in Gdansk, Poland. Arch Med Sci 2018; 14: 22-9.

17. Daar G, Sarı K, Gencer ZK, Ede H, Aydın R, Saydam L. The relation between childhood obesity and adenotonsillar hypertrophy. Eur Arch Otorhinolaryngol 2016; 273: 505-9. 
18. Schwab RJ, Pasirstein M, Pierson R, et al. Identification of upper airway anatomic risk factors for obstructive sleep apnea with volumetric magnetic resonance imaging. Am J Respir Crit Care Med 2003; 168: 522-30.

19. Zong J, Liu Y, Huang Y, et al. Serum lipids alterations in adenoid hypertrophy or adenotonsillar hypertrophy children with sleep disordered breathing. Int J Pediatr Otorhinolaryngol 2013; 77: 717-20.

20. Punjabi NM. The epidemiology of adult obstructive sleep apnea. Proc Am Thorac Soc 2008; 5: 136-43.

21. Wang JH, Chung YS, Cho YW, et al. Palatine tonsil size in obese, overweight, and normal-weight children with sleep-disordered breathing. Otolaryngol Head Neck Surg 2010; 142: 516-9.

22. Arens R, Sin S, Nandalike K, et al. Upper airway struc ture and body fat composition in obese children with obstructive sleep apnea syndrome. Am J Respir Crit Care Med 2011; 183: 782-7. 